\title{
How effectively bonding evolution theory retrieves and visualizes curly arrows: The cycloaddition reaction of cyclic nitrones
}

\author{
Abel I. Adjieufack ${ }^{1}$ () | Maraf Mbah Bake ${ }^{1}$ | Joseph Ketcha Mbadcam ${ }^{1}$ | \\ Ibrahim Mbouombouo Ndassa ${ }^{2}$ ( ) | Juan Andrés ${ }^{3}$ | Mónica Oliva ${ }^{3}$ | Vicent S. Safont ${ }^{3}$
}

${ }^{1}$ Physical and Theoretical Chemistry Laboratory, Faculty of Science, University of Yaoundé I, Yaoundé, Cameroon

${ }^{2}$ Department of Chemistry, High Teacher Training College, University of Yaoundé I, Yaoundé, Cameroon

${ }^{3}$ Departament de Química Física i Analítica, Universitat Jaume I, Castelló, Spain

\section{Correspondence}

Vicent S. Safont, Departament de Química Física i Analítica, Universitat Jaume I, Avda. Sos Baynat s/n, 12071 Castelló, Spain.

Email: safont@qfa.uji.es

Ibrahim Mbouombouo Ndassa, Department of Chemistry, High Teacher Training College, University of Yaoundé I, P.O. Box 47 Yaoundé, Cameroon.

Email: indassa@yahoo.fr

Funding information

Fonds De La Recherche Scientifique - FNRS, Grant/Award Numbers: FRFC Convention 2.4.617.07.F, FRFC Convention 2.5020.11; Ministerio de Economía y Competitividad, Grant/Award Number: CTQ2015-65207-P; Universitat Jaume I, Grant/Award Number: UJI-B2016-25; Université de Namur, Grant/ Award Number: UNamur-CERUNA Mobility Fellowship

\begin{abstract}
In the present work, the electron density flows involved throughout the progress of the four reaction pathways associated with the intramolecular [3 + 2] cycloaddition of cyclic nitrones Z-1 and E-1 are analyzed using the bonding evolution theory. The present study highlights the nonconcerted nature of the processes, which can be described as taking place in several stages. The first stage consists in the depopulation of the initial $\mathrm{C}=\mathrm{N}$ and $\mathrm{C}=\mathrm{C}$ double bonds to render the $\mathrm{N}$ lone pair and the corresponding $\mathrm{C}-\mathrm{N}$ and $\mathrm{C}-\mathrm{C}$ single bonds, and these electronic flows initiate the reactions. The $\mathrm{C}-\mathrm{C}$ and $\mathrm{C}-\mathrm{O}$ sigma bond formations take place later on, once the transition states have been overcome. Along the bridged pathways, the $\mathrm{C}-\mathrm{C}$ bond formation process precedes the $\mathrm{O}-\mathrm{C}$ bond formation event, although, along the fused paths, the $\mathrm{O}-\mathrm{C}$ bond formation process occurs first and the formation of the $\mathrm{C}-\mathrm{C}$ bond is the last electronic flow to take place. Finally, curly arrow representations accounting for the timing of the electron flows are obtained from the bonding evolution theory results.
\end{abstract}

\section{KEYWORDS}

bonding evolution theory, curly arrows, cyclic nitrones, intramolecular [3+2]cycloaddition

\section{1 | INTRODUCTION}

Over the last few decades, the scope of quantum-chemical methods has grown substantially and it is nowadays possible to compute and quantitatively characterize the electronic structure of ever larger and more complex molecules. In theoretical and computational chemistry, the study of some aspects of the molecular electronic structure, such as the chemical reactivity or the nature of the chemical bond, rely upon the analysis of the wave function or electron density. Today, quantum chemical methodologies are routinely employed to map the potential energy surfaces of reactive systems to find the reaction path that connects the reactants to products, via the corresponding transition states (TSs) and possible intermediates, thus allowing a quantitative description of the mechanisms, energetics, and dynamics governing chemical reactions involving relatively large polyatomic systems. The acquired knowledge has proven to be critical to gain a deeper understanding of many chemical processes and transformations; however, the fundamental features of the formation and cleavage of chemical bonds throughout the reaction mechanisms 
of a given chemical rearrangement, as essential concepts in controlling reaction rates, are still extremely controversial. The underlying reason for this is the fact that no physical observable, associated with the chemical bond and subsequent chemical bond breaking/forming events, exists. Therefore, theoretically speaking, the chemical bond is a noumenon, and is itself a fuzzy concept that is not measurable and cannot therefore be defined. ${ }^{[1-6]}$ Even though it is chemically significant and conceptually relevant in the comprehension of molecular behaviors and chemical reactivity, it is an object of purely rational apprehension and intellectual intuition.

As Ayers et al very recently pointed out, it is helpful to define chemical concepts directly in terms of observable. ${ }^{[7]}$ This is why the electron density, $\rho(r)$, is certainly the best choice because it is a local function defined within the exact many-body theory, which can also be extracted from experimental data as well as from first principles methods. From a quantum perspective, the importance of $\rho(r)$, as a fundamental property of an electronic system containing all the information of physical relevance, is highlighted by the Hohenberg-Kohn theorem, ${ }^{[8]}$ that is, all ground state properties depend on the charge density. In this sense, a relevant approach for studying a given chemical process is provided by a topology perspective. ${ }^{[9]}$ In particular, Bader ${ }^{[4,10]}$ introduced quantum chemical topology (QCT), ${ }^{[11]}$ based on the study of the topology of a molecular scalar field, which condenses the chemically relevant information obtained from quantum calculations into one single intuitive real space function. In the QCT framework, Krokidis and Silvi ${ }^{[12]}$ have developed the bonding evolution theory (BET), which associates the topological analysis of the electron localization function (ELF) ${ }^{[13]}$ with Thom's catastrophe theory. ${ }^{[14]}$ BET is an appropriate tool for the study of organic reaction mechanisms, particularly to characterize the reorganization of electron pairing during the reaction mechanism, and makes it possible to perceive the electronic rearrangement and bonding changes taking place along a reaction path. ${ }^{[15-19]}$

Despite widespread usage for analysis and visualization purposes, the curly arrows representation is intrinsically tied to the localized Lewisstructural picture and describes chemical transformations from reactants to products via transition states and possible intermediates along a chosen reactive pathway. In this context, it is important to recover a seminal work by Moyano et al, ${ }^{[20]}$ published in 1987, not very cited, in which the authors use the concept of localized molecular orbitals and their evolution along the reaction progress to describe the "movement" of bond orbitals and/or lone pairs, directly related to the "curled arrow" picture. Later, Lledós et al have shown that the motion of the centroids of localized orbitals along the intrinsic reaction coordinate (IRC) can be correlated with the curly arrows representing the electron motions as the reaction takes place. ${ }^{[21-24]}$ At the same time, Knizia et al have presented the so-called intrinsic bonding orbitals, that can be associated with a nonempirical form of localized molecular orbitals to calculate the electron flow in many reaction mechanisms, ${ }^{[25-28]}$ while Ponec ${ }^{[29]}$ has demonstrated, based on the paper of Salem, ${ }^{[30]}$ the relationship between the electron reorganization during the reaction with the shifts of electron pairs, exemplifying the so-called "curved arrow formalism." Very recently Schmidt et $\mathrm{al}^{[31]}$ have demonstrated that the analysis of any electronic wave-function in terms of the tiling along a reaction coordinate reveals the electron movements depicted by the curly arrow notation for several reaction.

From the viewpoint of the BET, a chemical reaction can be described as a sequence of elementary chemical processes separated by turning points, or catastrophes. By identifying these turning points connecting the different ELF structural stability domains (SSDs) along the reaction pathway it becomes possible to perform a rigorous characterization of the sequence of electron pair rearrangements taking place during a chemical transformation, such as multiple bond forming/breaking processes, creation/annihilation of lone pairs, transformations of double bonds into single ones or vice versa, and other electronic rearrangements. Our groups are engaged in a research project dedicated to the analysis of complex reaction mechanisms, such as the 1,3-dipolar cycloadditions between cyclic nitrones and ethyl acrylate, ${ }^{[32]}$ the intramolecular [3 +2 ] cycloaddition reactions of unsaturated nitrile oxides, ${ }^{[33]}$ the denitrogenation process of 2,3-diazabicyclo[2.2.1] hept-2-ene derivatives, ${ }^{[34]}$ or the thermal Claisen rearrangement, ${ }^{[35]}$ with emphasis on how curly arrows express electron flow and reaction mechanisms. ${ }^{[36,37]}$

The topological techniques for evaluating reaction mechanisms have also been used by other groups. In particular, the reaction between nitrones and isocyanates was described making use of noncovalent interactions ( $\mathrm{NCl}$ ) and ELF studies ${ }^{[38]}$ while the evolution of ELF along the reaction was analyzed for the [3 + 2] cycloaddition reactions of nitrones with electron-deficient ethylenes ${ }^{[39]}$ or ketenes, ${ }^{[40]}$ as well as for the $[3+2]$ cycloaddition reactions of C,N Dialkyl nitrones with ethylene derivatives. ${ }^{[41]} \mathrm{A}$ review on the analysis of the ELF evolution associated to nitrones reactivity has been presented recently, highlighting the sequential way of formation of the bonds. ${ }^{[42]}$ Similar reactions have been studied for explicitly evaluating the synchronicity by using ELF. ${ }^{[43]}$

Hodges et $\mathrm{al}^{[44]}$ and some members of our group ${ }^{[45]}$ have studied experimentally and theoretically, respectively, the intramolecular [3 +2 ] cycloaddition reactions of cyclic nitrones Z-1 and E-1. Four reaction paths are possible (Scheme 1), depending on the formation of the O1-C5 or 01-C4 sigma bonds for fused or bridged reaction paths, respectively, and with the exo or endo orientation of the substituent.

The present study offers a detailed chemical insight into the progress of the intramolecular cycloaddition of Z-1 and E-1 cyclic nitrones, from the perspective of BET, with emphasis on how curly arrows reflect electron density transfers in chemical reaction mechanisms. The focus has never been placed on a topology perspective for such chemical rearrangements, despite the idea that BET may carry information in terms of the electronic redistribution throughout the reaction progress. This, therefore, offers the possibility of retrieving the description based on the curly arrows of the corresponding reaction mechanism.

Therefore, the main goals of this study are to identify the sequence of chemical events taking place along the reaction pathway and to propose a curly arrow diagram for the electronic rearrangement based on the BET analysis. This will allow us to address and answer some new questions: (a) Where and how does charge transfer take place along the reaction progress? (b) How does electron density rearrange and how can this rearrangement be associated with chemical events such as the breaking/forming of chemical bonds, throughout the reaction progress? (c) How 


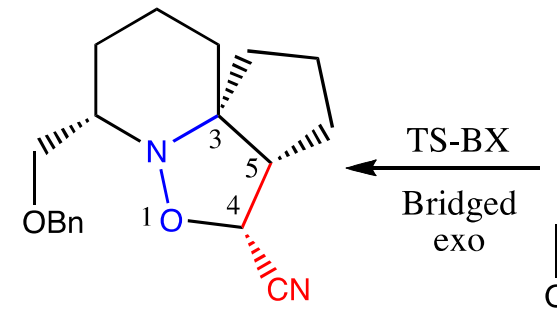

CaB exo

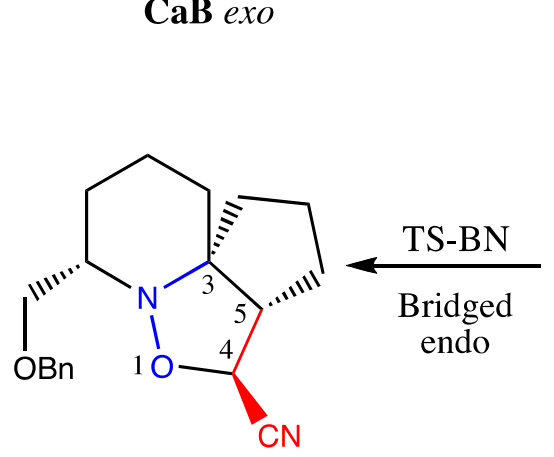

$\mathbf{C a B}$ endo<smiles>[Z1]CCCC1=[N+]([O-])[C@@H](COCc2ccccc2)CCC1</smiles>

Isomerisation $\mathrm{Z} / \mathrm{E}$

CaF exo<smiles>CC(C)[C@H](COCc1ccccc1)N=C/C=C/CCCC1=[N+]([O-])[C@@H](COc2ccccc2)CCC1</smiles>

SCHEME 1 Different reaction pathways of the intramolecular [3 + 2] cycloaddition reaction of cyclic nitrones

could the electronic reorganization proceed along the reaction path? Or, in other words, what types of catastrophes appear along each reaction pathway during the BET? (d) What is the nature of the chemical mechanism along the reaction pathway: is it synchronous or asynchronous?

\section{2 | METHODS OF CALCULATION}

All geometry optimizations were performed through density functional theory calculations using the MPWB1K ${ }^{[46]}$ functional as implemented in the Gaussian 16 program, ${ }^{[47]}$ together with the standard $6-311 \mathrm{G}(\mathrm{d}, \mathrm{p})$ basis set. ${ }^{[48]}$ The whole set of Cartesian coordinates for the 10 stationary points are reported as supporting information, after a brief introduction to the theoretical background on which the BET is based. The absolute and relative energies for these points are also collected there (Table S1). The intrinsic reaction coordinate (IRC) paths ${ }^{[49]}$ were traced in order to check the energy profiles connecting each TS to the two associated minima of the proposed mechanism, using the second-order GonzálezSchlegel integration method. ${ }^{[50]}$ To perform the topological analysis within the BET theory, the wave function has been obtained for each point of the IRCs, and the ELF analysis has been performed using the TopMod package ${ }^{[51]}$ considering a grid of 0.2 Bohr. The ELF basin positions are visualized using the GaussView program ${ }^{[52]}$ and the evolution of the basin population along the IRC is viewed using Drawprofile. ${ }^{[53]}$

\section{RESULTS AND DISCUSSIONS}

\section{1 | BET analysis of the bridged exo channel}

The BET study of the bridged exo reaction pathway through TS-BX shows that the process takes place along six SSDs, as can be seen in Figure 1. In the SSD-I domain the system shows the presence of two disynaptic basins $\mathrm{V}(\mathrm{C} 4, \mathrm{C} 5)$ and $\mathrm{V}^{\prime}(\mathrm{C} 4, \mathrm{C} 5)$ between $\mathrm{C} 4$ and $\mathrm{C} 5$ atoms, thus evidencing the double bond linking between these two atoms at the nitrone Z-1 reactant, initially with a total population of $3.38|e|$. Two disynaptic basins $\mathrm{V}$ $(\mathrm{N} 2, \mathrm{C} 3)$ and $\mathrm{V}^{\prime}(\mathrm{N} 2, \mathrm{C} 3)$ have been found between $\mathrm{N} 2$ and $\mathrm{C} 3$ atoms, their total population being $3.90|e|$ initially, as expected for a double N2-C3 bond. A disynaptic $\mathrm{V}(\mathrm{O} 1, \mathrm{~N} 2)$ basin with 1.47 |e for an $\mathrm{O} 1-\mathrm{N} 2$ single bond, and two monosynaptic basins $\mathrm{V}(\mathrm{O} 1)$ and $\mathrm{V}^{\prime}(\mathrm{O} 1)$ associated to $\mathrm{O} 1$ oxygen lone pairs and integrating a total of $5.93|e|$ have also been found (the whole set of basin populations at the initial and final point of each one of the SSDs found are collected in Table S2, together with the corresponding IRC coordinates values and the catastrophe types).

At the turning point between SSD-I and SSD-II, the two basins $\mathrm{V}(\mathrm{N} 2, \mathrm{C} 3)$ and $\mathrm{V}^{\prime}(\mathrm{N} 2, \mathrm{C} 3)$ merge into one with a population of $3.83|e|$, illustrating the transformation of the double bond into a single one. This topological change corresponds to a Cusp (C) catastrophe. The reduction in the $\mathrm{V}$ $(\mathrm{N} 2, \mathrm{C} 3)$ basin population starts at the SSD-III, with the simultaneous creation of the two new monosynaptic V(C3) and V(N2) basins (Fold-type 


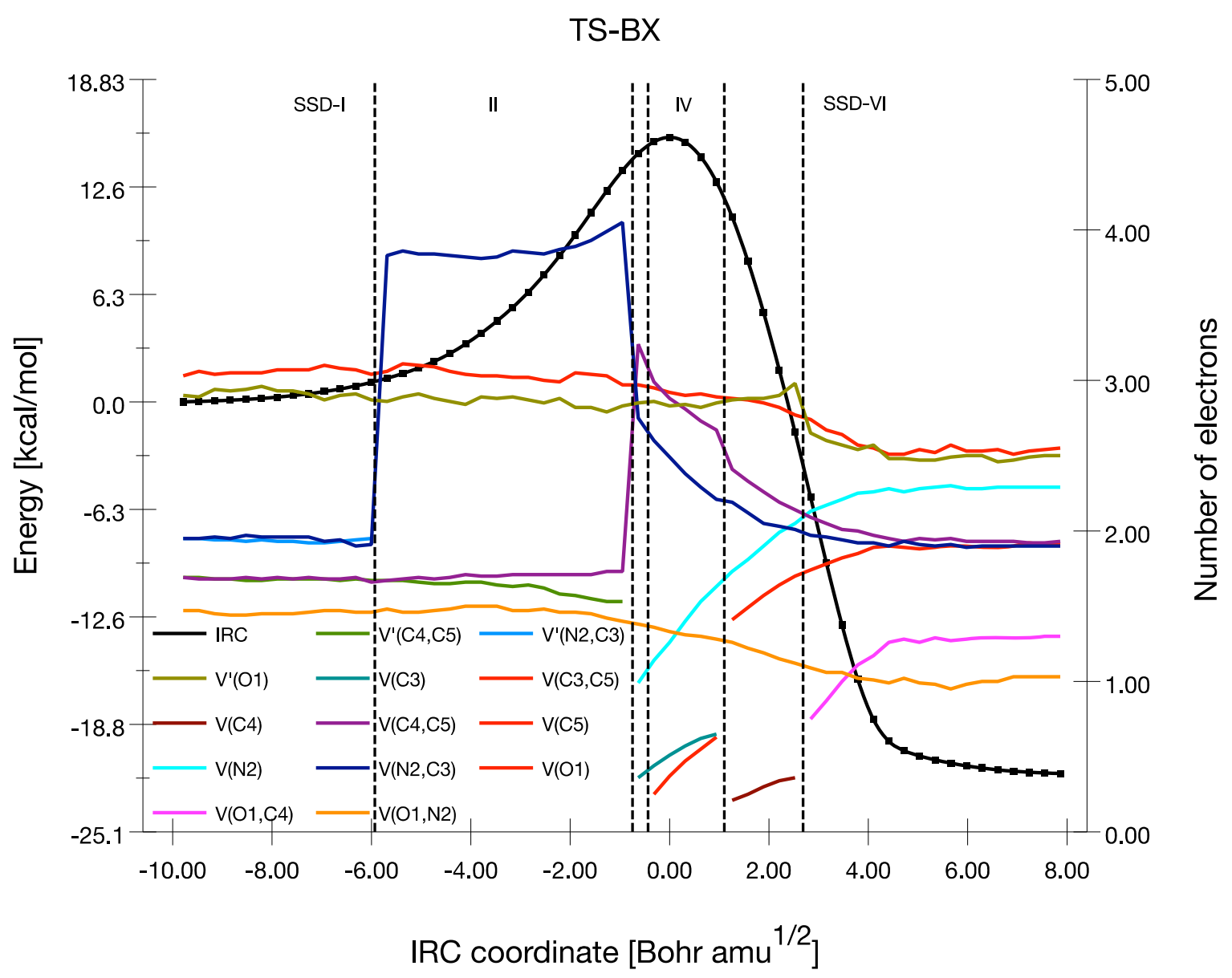

FIGURE 1 Relative energy (black line with dots, $\mathrm{kcal} / \mathrm{mol}$ ) along the IRC path associated with TS-BX as a function of its coordinate value (in Bohr $a m u^{1 / 2}$ ). The endpoint of IRC along the reverse direction has been taken as the reference energy. Evolution of the population (in electrons) of selected basins along the IRC. Dashed vertical lines indicate the frontiers between the SSDs found. IRC, intrinsic reaction coordinate; SSD, structural stability domain

catastrophe, $\mathrm{F}$ ) with 0.36 and $0.99|e|$, respectively, as populations. Furthermore, a $\mathrm{C}$ catastrophe takes place in the same domain with the merging of the two $\mathrm{V}(\mathrm{C} 4, \mathrm{C} 5)$ and $\mathrm{V}^{\prime}(\mathrm{C} 4, \mathrm{C} 5)$ basins belonging to the double bond $\mathrm{C} 4=\mathrm{C} 5$ to give a single $\mathrm{V}(\mathrm{C} 4, \mathrm{C} 5)$ basin integrating $3.24|e|$.

In the SSD-IV domain, the reduction of the $\mathrm{V}(\mathrm{C} 4, \mathrm{C} 5)$ basin population begins and generates the appearance of an $\mathrm{F}$ catastrophe with the creation of the new monosynaptic $\mathrm{V}(\mathrm{C} 5)$ basin with $0.25|e|$, which, together with the $\mathrm{V}(\mathrm{C} 3)$ monosynaptic basin, will be responsible for the formation of the $\mathrm{V}(\mathrm{C} 3, \mathrm{C} 5)$ disynaptic basin (see Figure 2). At the end of this domain, the populations of $\mathrm{V}(\mathrm{C} 3)$ and $\mathrm{V}(\mathrm{N} 2)$ reach 0.63 and $1.63|e|$, respectively. At the beginning of the SSD-V domain, the two monosynaptic basins $\mathrm{V}(\mathrm{C} 3)$ and $\mathrm{V}(\mathrm{C} 5)$, created in the previous domains SSD-III and IV, merge together by means of a $\mathrm{C}$ catastrophe to form the $\mathrm{V}(\mathrm{C} 3, \mathrm{C} 5)$ disynaptic basin holding $1.41|e|$, thus describing the first main topological change (formation of the C3- C5 sigma bond). Another F catastrophe also appears in this domain: the creation of the monosynaptic $\mathrm{V}(\mathrm{C} 4)$ basin with $0.21|e|$.

The formation of the $\mathrm{V}(\mathrm{O} 1, \mathrm{C} 4)$ basin is the last topological change, appearing in the SSD-VI domain and accounting for the O1-C4 bond formation by means of another C-type catastrophe. At the beginning of SSD-VI, the $\mathrm{V}(\mathrm{O} 1, \mathrm{C} 4)$ basin has a total of 0.75 electrons that are mainly taken from the disappearing $\mathrm{V}(\mathrm{C} 4)$ basin, $0.36|e|$, and also from the $\mathrm{V}(\mathrm{O} 1)$ basin, whose population diminishes by $0.33|e|$.

\section{2 | BET analysis of the fused exo channel}

We have also explored the BET along the fused exo reaction pathway through TS-FX. This analysis reveals that in this case the IRC can be divided into seven domains, as can be seen in Figure 3.

As before, the SSD-I domain displays the Z-1 nitrone reactant topology (see Figure 4). The transition between the SSD-I and SSD-II domains takes place by means of a $\mathrm{C}$ catastrophe that is due to the transformation of the two $\mathrm{V}(\mathrm{N} 2, \mathrm{C} 3)$ and $\mathrm{V}^{\prime}(\mathrm{N} 2, \mathrm{C} 3)$ basins into one with a total population of $3.9|e|$ (Figure 3, Table S3). Afterward, in SSD-III, the same topological change takes place involving the basins $\mathrm{V}(\mathrm{C} 4, \mathrm{C} 5)$ and $\mathrm{V}^{\prime}(\mathrm{C} 4, \mathrm{C} 5)$. 

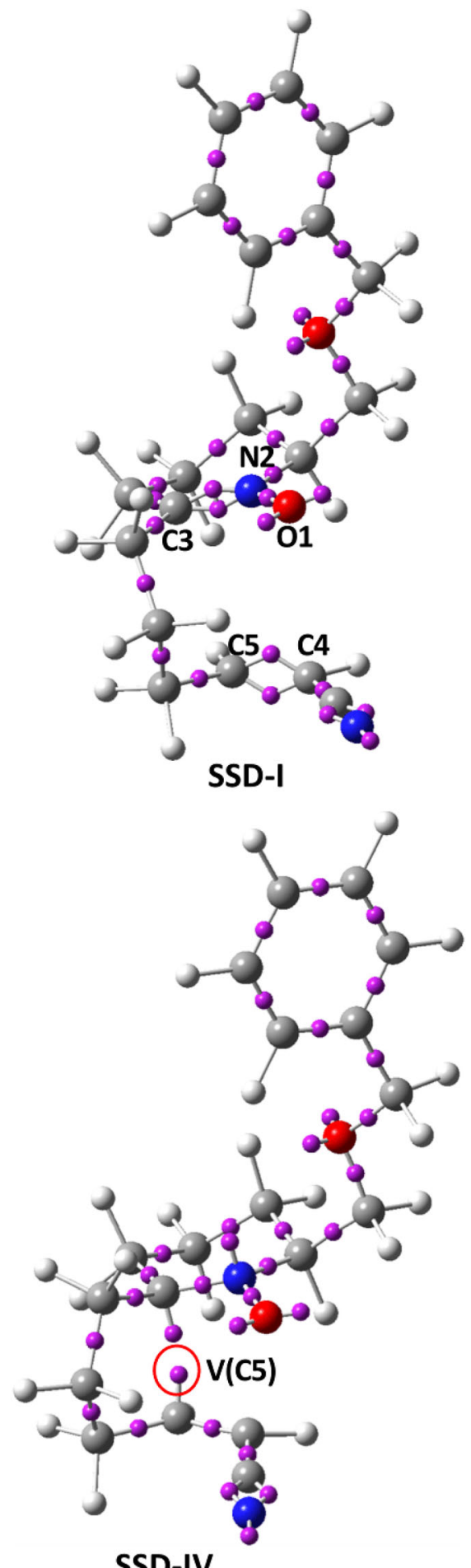

SSD-IV

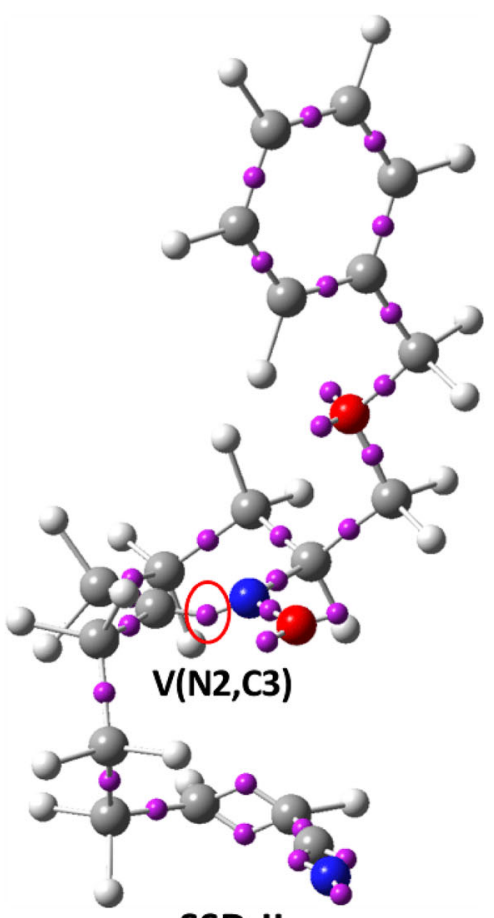

SSD-II

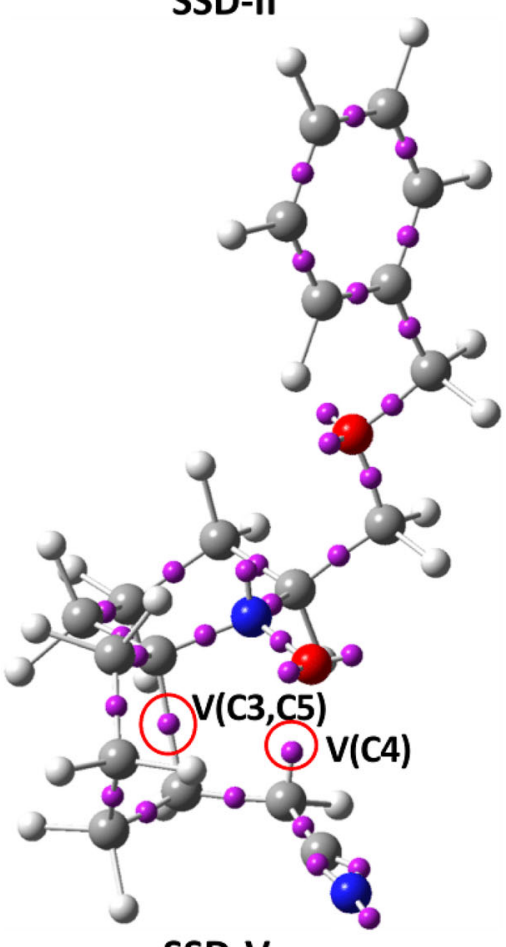

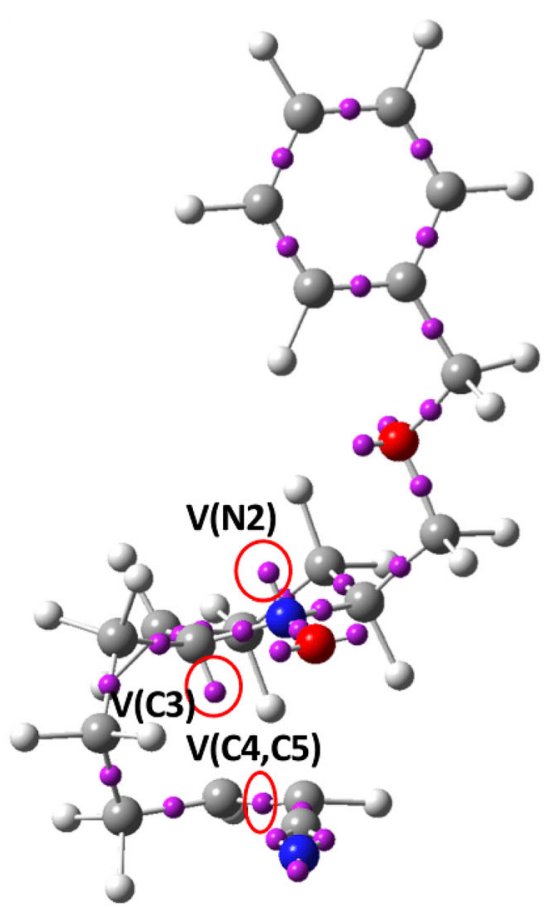

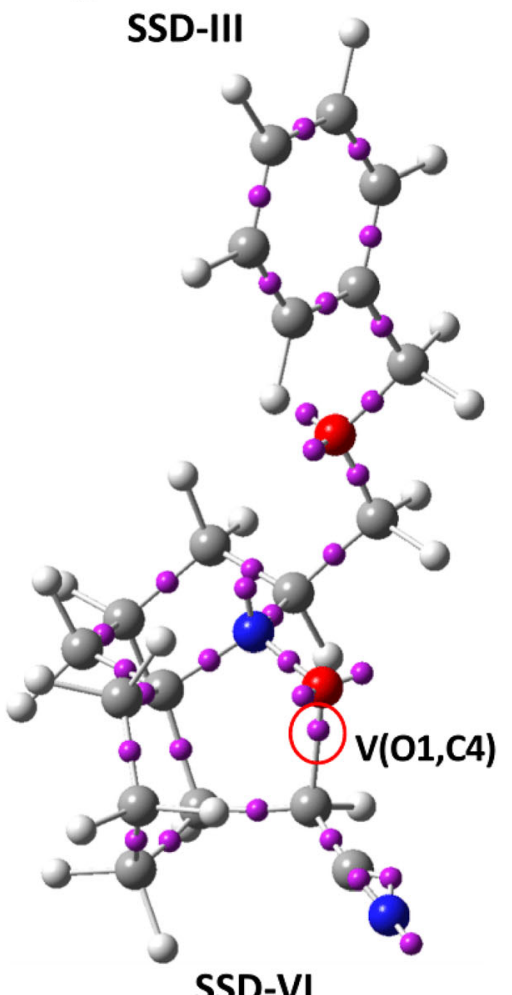

FIGURE 2 ELF attractor positions for selected points that are representative of each of the SSDs found along the IRC associated with TS-BX. Gray, blue, and red spheres represent the $\mathrm{C}, \mathrm{N}$, and $\mathrm{O}$ core basins, respectively, while violet spheres are mono- or disynaptic basins and white spheres depict the hydrogenated basins. The red ellipse has been used to highlight the topological changes encountered. SSD, structural stability domain

On the other hand, the SSD-IV and SSD-V domains are characterized by the creation of the V(N2) and V(C4) monosynaptic basins, respectively, reflecting the appearance of the lone pair on the nitrogen atom N2 and a pseudo radical center around the C4 atom. At the end of SSD-V, the populations of these two basins reach $1.65|e|$ for $\mathrm{V}(\mathrm{N} 2)$ and $0.63|e|$ for $\mathrm{V}(\mathrm{C} 4)$. At the beginning of SSD-VI, two $\mathrm{F}$ catastrophes can be sensed, consisting in the appearance of the monosynaptic $\mathrm{V}(\mathrm{C} 3)$ basin as well as the appearance of the disynaptic $\mathrm{V}(\mathrm{O} 1, \mathrm{C} 5)$, with populations of 


\section{TS-FX}

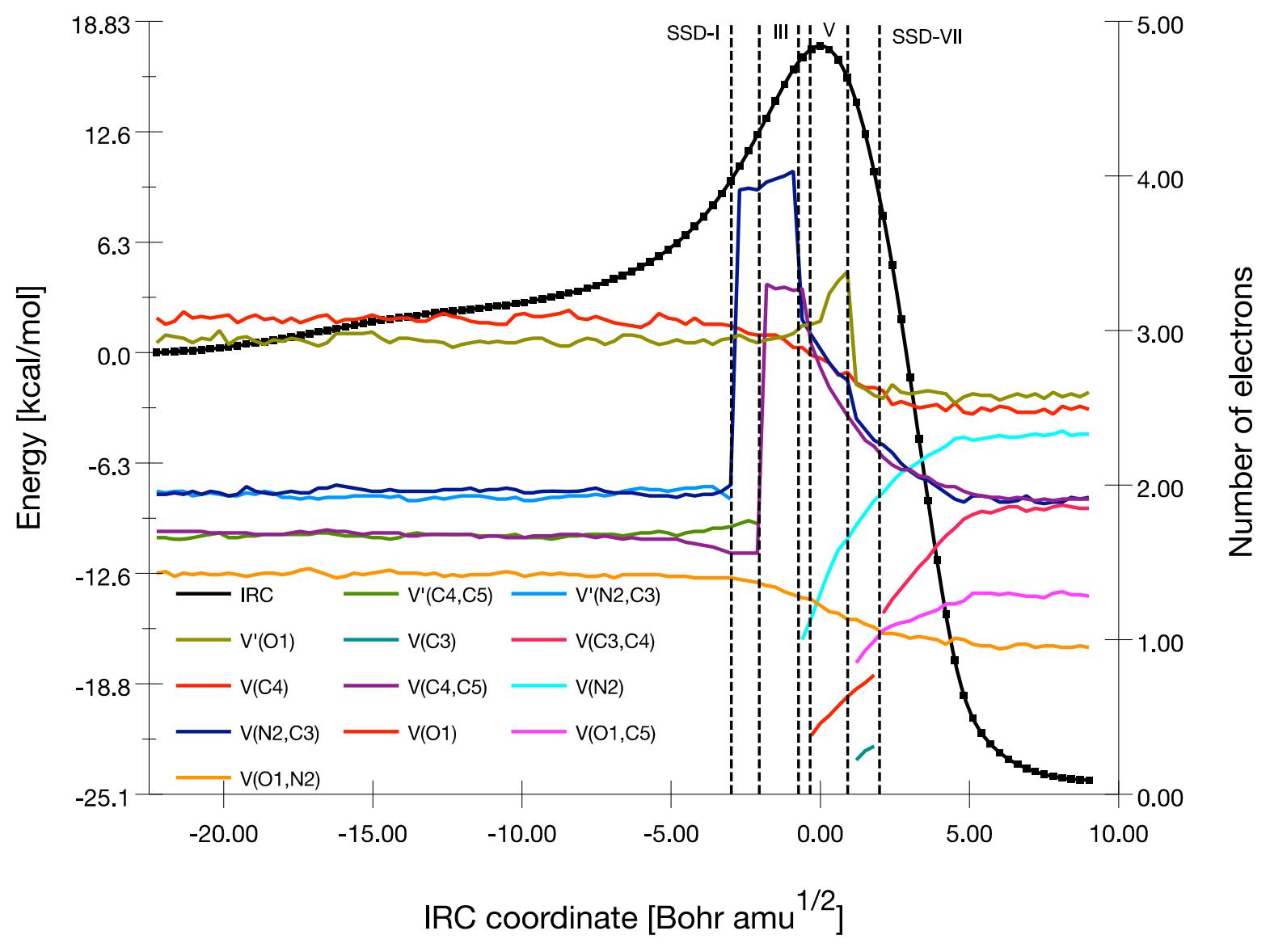

FIGURE 3 Relative energy (black line with dots, $\mathrm{kcal} / \mathrm{mol}$ ) along the IRC path associated with TS-FX as a function of its coordinate value (in Bohr $\mathrm{amu}^{1 / 2}$ ). The end point of IRC along the reverse direction has been taken as the reference energy. Evolution of the population (in electrons) of selected basins along the IRC. Dashed vertical lines indicate the frontiers between the SSDs found. SSD, structural stability domain

$0.23|e|$ and $0.85|e|$, respectively, illustrating the first significant topological change, which corresponds to the formation of the $\mathrm{O} 1-\mathrm{C} 5$ bond. The population of this $\mathrm{V}(\mathrm{O} 1, \mathrm{C} 5)$ basin comes from the reduction in populations of the $\mathrm{V}^{\prime}(\mathrm{O} 1), \mathrm{V}(\mathrm{O} 1)$, and $\mathrm{V}(\mathrm{C} 4, \mathrm{C} 5)$ basins, which lose 0.69 , 0.07 , and $0.08|e|$, respectively, at the beginning of this domain. It should be noted that at the end of the SSD-VI domain, the populations of the $\mathrm{V}(\mathrm{C} 3)$ and $\mathrm{V}(\mathrm{C} 4)$ monosynaptic basins are quite large and are thus ready to merge with each other in order to form the C3-C4 bond in the last domain.

Once populated, these two $\mathrm{V}(\mathrm{C} 3)$ and $\mathrm{V}(\mathrm{C} 4)$ basins merge at the turning point between SSD-VI and SSD-VII to generate the disynaptic basin $\mathrm{V}(\mathrm{C} 3, \mathrm{C} 4)$ in a $\mathrm{C}$ catastrophe, illustrating the last topological change and the $\mathrm{C} 3-\mathrm{C} 4$ bond formation. The population of this basin $\mathrm{V}(\mathrm{C} 3, \mathrm{C} 4)$ is 1.17 $|e|$ at the beginning but reaches a value of $1.85|e|$ at the last point in the domain.

It is also worth noting the different order in which the $\mathrm{C}-\mathrm{C}$ and $\mathrm{O}-\mathrm{C}$ bonds are formed depending on the process: for the 6,5,5-adduct (CaB) formation through the bridged exo path via the TS-BX, the C3-C5 bond is formed prior to the O1-C4 bond, while for the 6,6,5-adduct (CaF) formation through the fused exo path via TS-FX, the inverse order was found. In both cases these bond formations take place after the TS has been passed, in the two last domains found throughout the process.

\section{3 | BET analysis of the endo channels}

We have also explored the endo channels: the bridged endo path through TS-BN as well as the fused endo process via TS-FN, for the intramolecu$\operatorname{lar}[3+2]$ cycloaddition reaction of the cyclic nitrone $E-1$. In so doing, the following observations were obtained:

For the regioisomeric channel through TS-BN, the reaction process is subdivided into eight domains of structural stability (Figure 5).

Figure 6 below illustrates the order of appearance and disappearance of the different mono- and disynaptic basins along the bridged endo reactive channel through TS-BN. Compared with the results obtained for the other bridged pathway, via TS-BX, small differences in the timing of the 


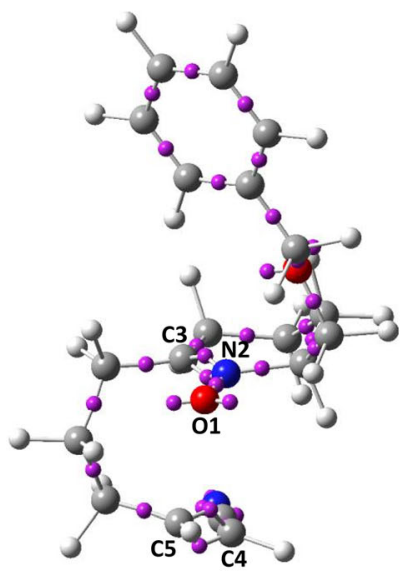

SSD-I
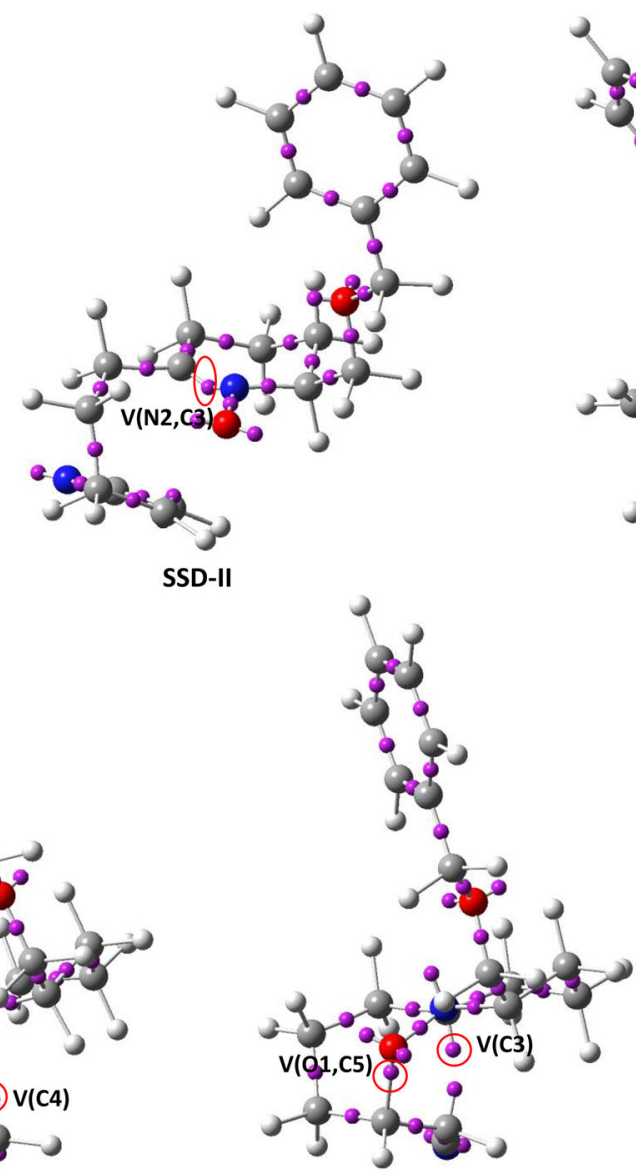

SSD-VI

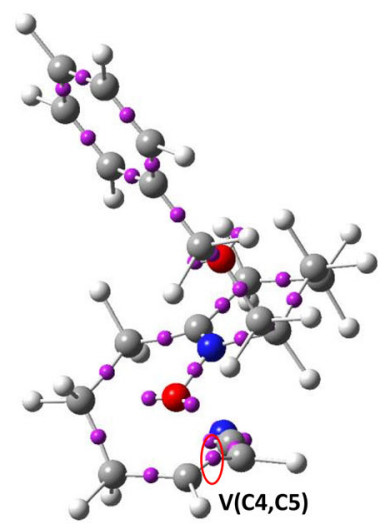

SSD-III

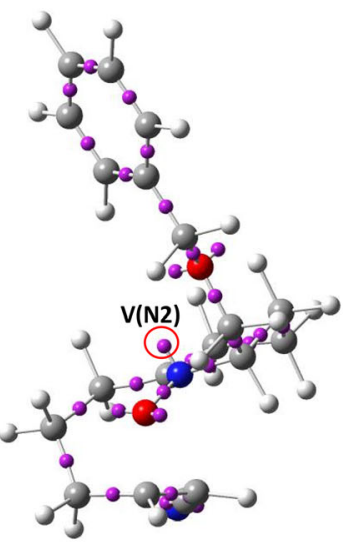

SSD-IV

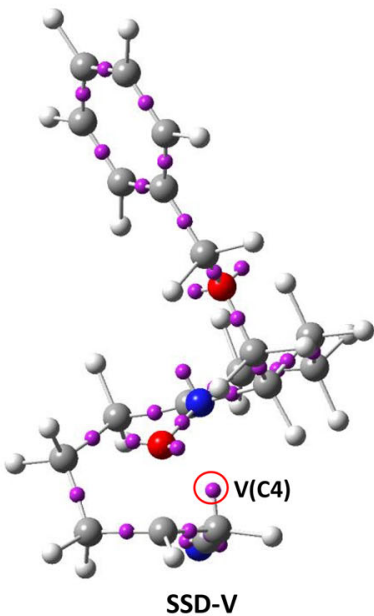

FIGURE 4 ELF attractor positions for selected points that are representative of each of the SSDs found along the IRC associated with TS-FX. SSD, structural stability domain

catastrophes taking place can be observed: on the one hand, the merging of the two disynaptic basins between $\mathrm{C} 4$ and $\mathrm{C} 5$ now takes place in the catastrophe between SSD-II and SSD-III, while the appearance of the monosynaptic basins V(C3) and V(N2) occurs at the turning point between SSD-III and SSD-IV. These three topological changes took place at the same time in the previous TS-BX channel. A similar observation can be made with respect to the formation of the disynaptic $\mathrm{V}(\mathrm{C} 3-\mathrm{C} 5)$ basin and the appearance of the monosynaptic $\mathrm{V}(\mathrm{C} 4)$ basin: these two changes now take place at different moments. The first one occurs at the turning point between SSD-V and SSD-VI, while the second happens at the catastrophe between SSD-VI and SSD-VII. Despite these differences, the V(C3,C5) and V(O1,C4) disynaptic basins reflecting the formation of the C3-C5 and O1-C4 bonds appear in later domains (VI and VIII), well after the TS has been passed, following the same tendency observed for the TS-BX case. The basin populations together with the IRC coordinate values as well as the catastrophe types have been collected in Table S4.

For the other regioisomeric endo channel via TS-FN, eight SSDs have also been found along the IRC (Figure 7 and Table S5). The first domains, SSD-I, II, and III, account for the same topology as in the preceding case (compare Figures 6 and 8). After that, the topological changes differ: now the order of appearance of the monosynaptic basins is $\mathrm{V}(\mathrm{N} 2)$, then $\mathrm{V}(\mathrm{C} 4)$, and finally $\mathrm{V}(\mathrm{C} 3)$, and the last two topological changes correspond to the formation of the $\mathrm{O} 1-\mathrm{C} 5$ and $\mathrm{C} 3-\mathrm{C} 4$ bonds. If the two fused channels (through TS-FN or TS-FX) are compared, the same trends are found, and only a small difference can be sensed, concerning the simultaneous appearances of $\mathrm{V}(\mathrm{C} 3)$ and $\mathrm{V}(\mathrm{O} 1, \mathrm{C} 5)$ taking place at the turning point between SSD-V and SSD-VI in the TS-FX case, while in the TS-FN path they take place consecutively. As before, it should be noted that the bond formations take place well after the TS has been passed, in late domains along the IRC.

\subsection{Evaluation of the synchronicity along the reaction channel for the intramolecular [3+2] cycloaddition of cyclic nitrones}

The concerted/nonconcerted process and synchronicity are fundamental concepts of chemical reactivity used to define the nature of the reaction mechanism of a given reaction. These concepts allow us to establish a temporal relationship between the chemical bond formation/breaking 


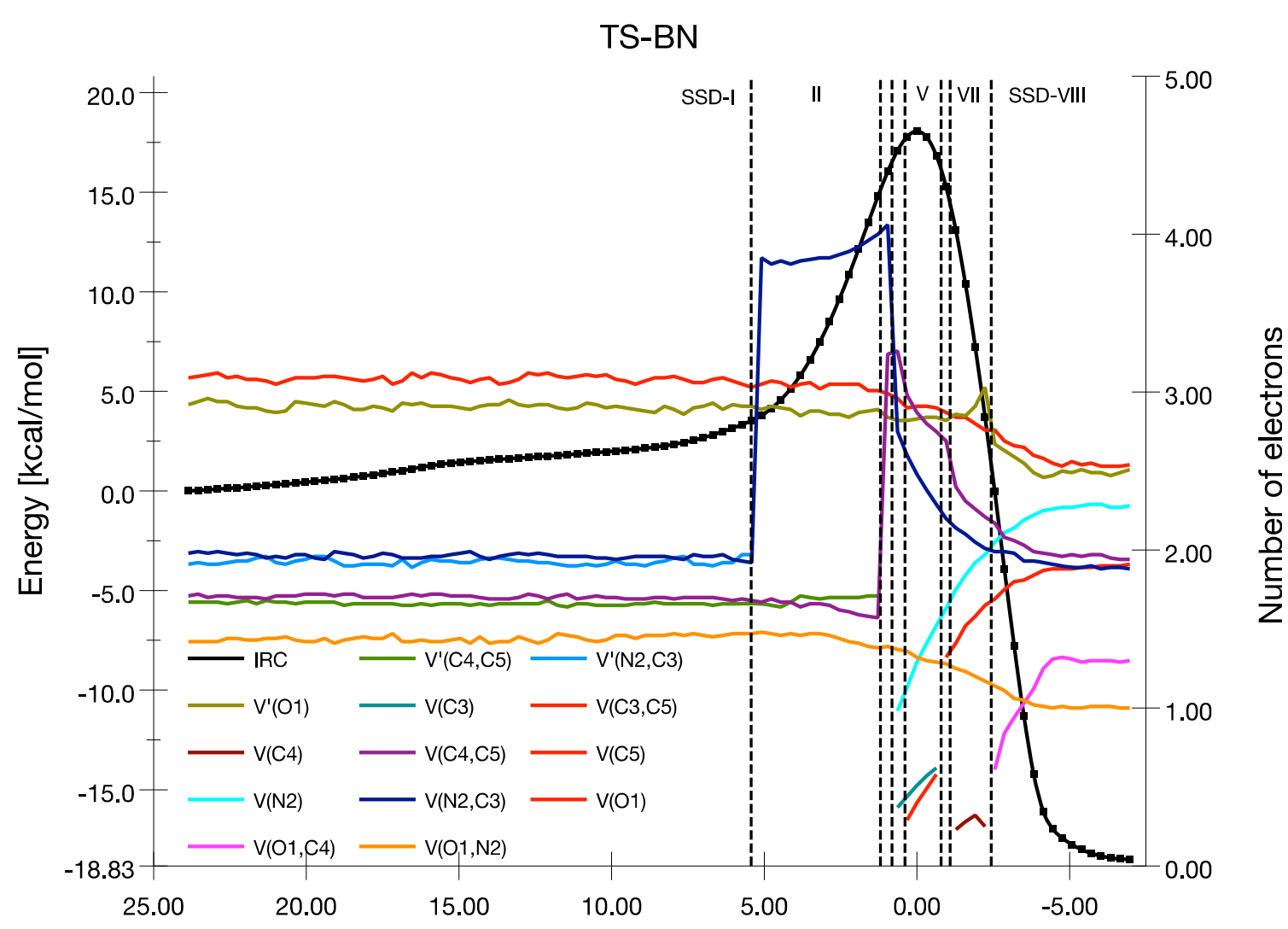

\section{IRC coordinate $\left[\right.$ Bohr amu $\left.{ }^{1 / 2}\right]$}

FIGURE 5 Relative energy (black line with dots, $\mathrm{kcal} / \mathrm{mol}$ ) along the IRC path associated with TS-BN as a function of its coordinate value (in Bohr $a m u^{1 / 2}$ ). The endpoint of IRC along the reverse direction has been taken as the reference energy. Evolution of the population (in electrons) of selected basins along the IRC. Dashed vertical lines indicate the frontiers between the SSDs found. IRC, intrinsic reaction coordinate, SSD, structural stability domain

processes along the reaction path. If these processes occur simultaneously, then the mechanism is defined as being synchronous and concerted, but if they occur at different times (one after another), the mechanism will be asynchronous.

A relationship between these temporal concepts and spatial quantities can be found by analyzing SSDs. To test the validity of this relationship, and using the position of changes between the different SSDs as an indicator of the synchronicity of a particular process, we defined ${ }^{\text {[32] }}$ the following equations to be used for a minimum of three SSDs. The synchronicity, $S_{y}$, can be calculated by the following Equation (1):

$$
S_{y}=1-\frac{2}{n(n-1)\left(S_{f}-S_{0}\right)} \sum_{i=1}^{n} \sum_{j=i+1}^{n}\left(S_{j}-S_{i}\right)
$$

where $n, S_{f}$, and $S_{0}$ are the number of SSDs minus one, the final IRC value, and the initial one, respectively, and the different values of $S_{j}$ and $S_{i}$ are the IRC values where the change between SSDs appear. The minimum value of $S_{y}$ will be a function of $n$ and can be obtained by Equation (2):

$$
S_{y}^{\min }=1-\frac{2\left(\sum_{i=1}^{n}(n-i)-\sum_{i=1}^{\frac{n}{2}}(n-2 i)\right)}{n(n-1)}
$$

Finally the absolute synchronicity, $S_{y}^{a b s}$, can be calculated through Equation (3) given by:

$$
S_{y}^{a b s}=\frac{S_{y}-S_{y}^{\min }}{1-S_{y}^{\min }}
$$

Table 1 contains the calculated values of the absolute synchronicities $\left(S_{y}^{a b s}\right)$, and the number of domains found for the four reaction pathways. 

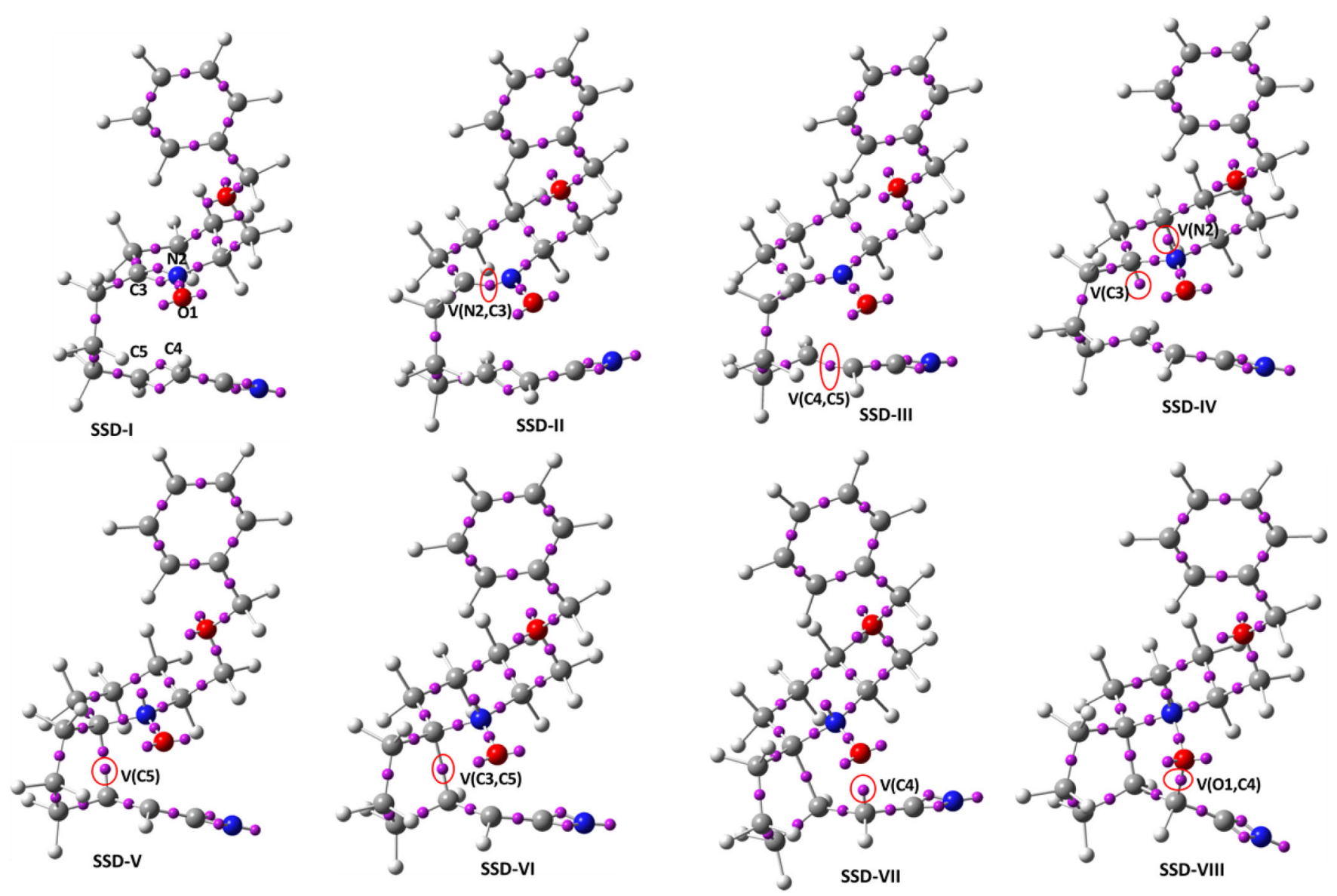

FIGURE 6 ELF attractor positions for selected points that are representative of each of the SSDs found along the IRC associated with TS-BN. SSD, structural stability domain

For the bridged exo channel through TS-BX, the IRC extends from -9.787 to $7.863 \mathrm{amu}^{1 / 2}$ Bohr. The SSD changes appear from left to right at the following IRC values, taken as the average between the last IRC value of one domain and the first IRC value of the next domain: -5.843 , $-0.789,-0.473,1.103$, and $2.683 \mathrm{amu}^{1 / 2}$ Bohr. From these values, the calculated values of $S_{y}$ and $S_{y}^{a b s}$ are 0.785 and 0.642 , respectively. The maximum value of absolute synchronicity, $S_{y}^{a b s}$, is 1 and the calculated value is $64.2 \%$ of this maximum, implying that these topological changes take place in a rather asynchronous manner. This is due to the early merging of the two $\mathrm{V}(\mathrm{N} 2, \mathrm{C} 3)$ and $\mathrm{V}^{\prime}(\mathrm{N} 2, \mathrm{C} 3)$ basins, which in the other four paths studied take place later on, closer to the other topological changes. If this early change is neglected, values of 0.887 and 0.830 for $S_{y}$ and $S_{y}^{a b s}$, respectively, would be found. On the other hand, the transition state TS-BX is found about halfway along the IRC (55.45\%) with an intermediate character between reagents and products.

For the channel via TS-FX, the TS is located at $71.19 \%$ along the IRC, with a more product-like nature. The IRC extends from -22.245 to $9.003 \mathrm{amu}^{1 / 2}$ Bohr and the SSD changes appear at $-2.858,-1.956,-0.752,-0.451,1.053$, and $1.955 \mathrm{amu}^{1 / 2}$ Bohr. In this case, the calculated values for $S_{y}$ and $S_{y}^{a b s}$ are 0.929 and 0.881 , respectively, and thus a far more synchronous process is described.

For the paths associated to TS-BN and TS-FN, the absolute synchronicities are 0.843 and 0.895 , respectively, while the synchronicities are 0.911 and 0.940 . Both are highly synchronous processes, like the TS-FX process. The TS-BN has an absolute synchronicity around $20 \%$ larger than TS-BX, while the TS-FN has an absolute synchronicity around 1.4\% larger than TS-FX. Like TS-BX, the two endo TSs have a product-like nature.

\subsection{Electron flows and curly arrows}

The data reported in Figures 1, 3, 5, and 7, and in Tables S2-S5, can be used to describe and depict the electron flows. Looking at these figures, it can be observed that the basin populations scarcely change along SSD-I, so that the electronic redistribution begins once the merging between the $\mathrm{V}(\mathrm{N} 2, \mathrm{C} 3)$ and $\mathrm{V}^{\prime}(\mathrm{N} 2, \mathrm{C} 3)$ basins has taken place. The variation in the population of the basins along SSD-II is minimal, and it is from the turning point between SSD-II and SSD-III that the electron flows gain importance. 


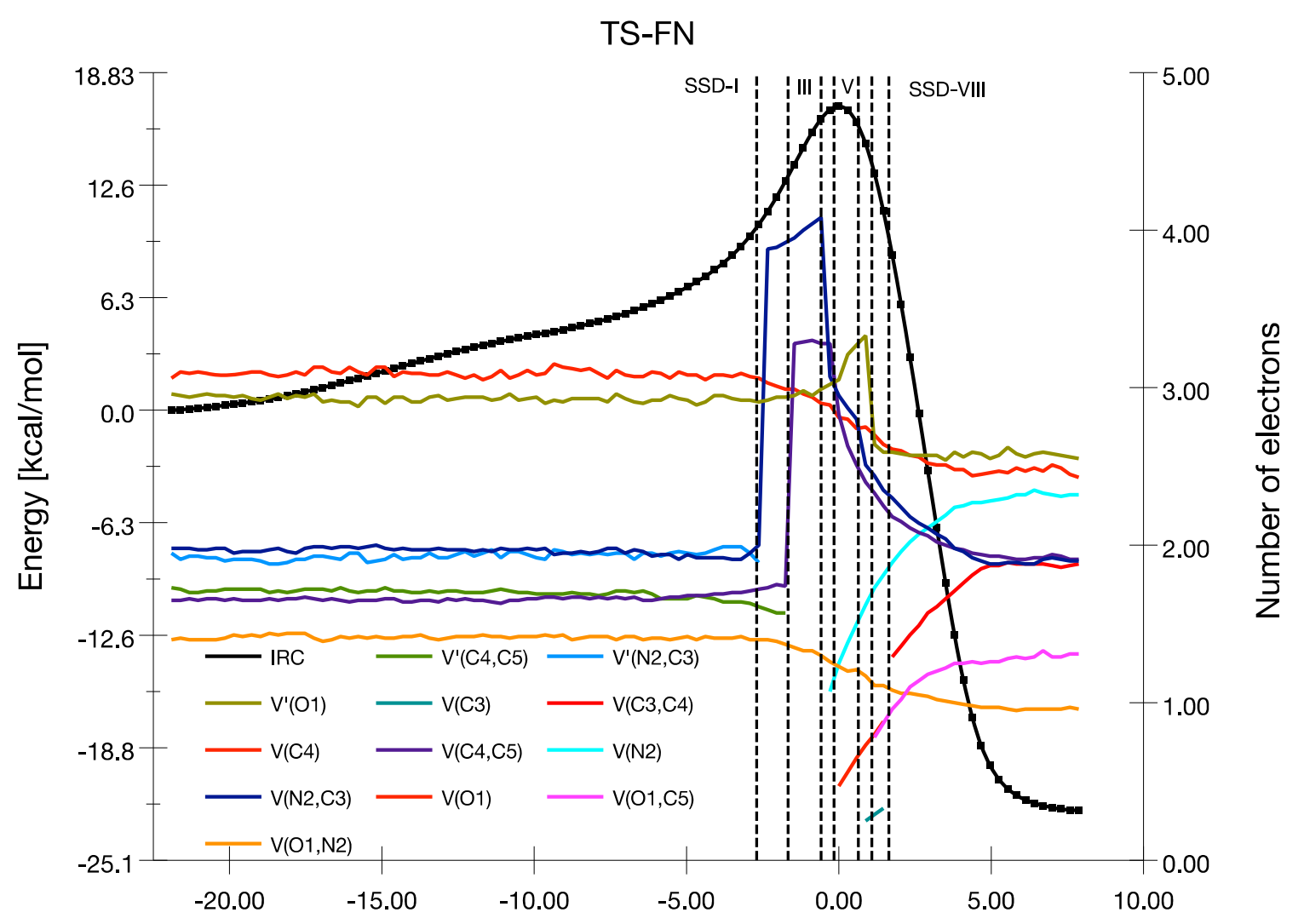

IRC coordinate $\left[\right.$ Bohr amu $\left.{ }^{1 / 2}\right]$

FIGURE 7 Relative energy (black line with dots, $\mathrm{kcal} / \mathrm{mol}$ ) along the IRC path associated with TS-FN as a function of its coordinate value (in Bohr $a m u^{1 / 2}$ ). The endpoint of IRC along the reverse direction has been taken as the reference energy. Evolution of the population (in electrons) of selected basins along the IRC. Dashed vertical lines indicate the frontiers between the SSDs found. SSD, structural stability domain

In the bridged exo case, through TS-BX, the population of both the $\mathrm{V}(\mathrm{N} 2)$ and $\mathrm{V}(\mathrm{C} 3)$ monosynaptic basins appearing at the turning point between SSD-II and SSD-III (a total of 1.35 |e|) comes mainly from the V(N2,C3) basin, which loses 1.12 le| at this turning point. A second electronic flow can be sensed at the turning point between SSD-III and SSD-IV when the V(C5) appears with 0.25 |e| taken mainly from V(C4,C5); along the SSD-IV domain the three monosynaptic basins continue to be populated from the same sources. Once the $\mathrm{V}(\mathrm{C} 3)$ and $\mathrm{V}(\mathrm{C} 5)$ basins acquire a relatively important population, they collapse into $\mathrm{V}(\mathrm{C} 3, \mathrm{C} 5)$, and in this way the $\mathrm{C} 3-\mathrm{C} 5$ sigma bond is formed. At the same time, a monosynaptic $\mathrm{V}(\mathrm{C} 4)$ basin appears, taking its population from $\mathrm{V}(\mathrm{C} 4, \mathrm{C} 5)$. The last change consists in the formation of $\mathrm{V}(\mathrm{O} 1, \mathrm{C} 4)$, the population being taken from the $\mathrm{V}(\mathrm{C} 4)$ basin that disappears and from $\mathrm{V}(\mathrm{O} 1)$, whose population decreases at the turning point between SSD-V and SSD-VI. To sum up, the electron flows leading from Z-1 to CaB exo can be divided into four stages, as depicted using curly arrows in Figure 9A: (a) depopulation of $\mathrm{V}(\mathrm{N} 2, \mathrm{C} 3$ ), giving rise to monosynaptic basins on $\mathrm{N} 2$ and on $\mathrm{C} 3$; (b) depopulation of $\mathrm{V}(\mathrm{C} 4, \mathrm{C} 5)$, with the creation of a monosynaptic basin on C5; (c) formation of the C3-C5 sigma bond from the C5 and C3 monosynaptic basins and creation of a C4 monosynaptic basin by depopulating the $\mathrm{C} 4-\mathrm{C} 5$ bond; and (d) formation of the O1-C4 sigma bond from the $\mathrm{C} 4$ and $\mathrm{O} 1$ monosynaptic basins.

In the bridged endo case, from $\mathrm{E}-1$ to $\mathrm{CaB}$ endo, the description is essentially the same, with the only difference being that there are five instead of four stages. As indicated in Figure 9B, stages 1) and 2) are the same, and in the third stage only the formation of the $\mathrm{C} 3-\mathrm{C} 5$ sigma bond from the C5 and C3 monosynaptic basins takes place; then in a fourth stage the creation of a C4 monosynaptic basin by depopulating the C4-C5 bond occurs; and the final stage consists in the formation of the O1-C4 sigma bond from the $\mathrm{C} 4$ and $\mathrm{O} 1$ monosynaptic basins.

In the fused exo case, through TS-FX, to reach CaF exo, the V(N2,C3) depopulates in a first stage to create only a monosynaptic basin on N2 with 1.00 le|. In a second step, the $\mathrm{V}(\mathrm{C} 4)$ basin is created taking its population, 0.38 le|, from the $\mathrm{V}(\mathrm{C} 4, \mathrm{C} 5)$ disynaptic basin. The third stage consists in several simultaneous electron flows: on the one hand, the $\mathrm{V}(\mathrm{C} 3)$ monosynaptic basin is created with 0.23 |e| mainly from $\mathrm{V}(\mathrm{N} 2$, $\mathrm{C} 3)$ while the $\mathrm{O} 1-\mathrm{C} 5$ bond is formed by the appearance of the $\mathrm{V}(\mathrm{O} 1, \mathrm{C} 5)$ disynaptic basin that takes its initial population, $0.85|\mathrm{e}|$, from $\mathrm{V}^{\prime}(\mathrm{O} 1), \mathrm{V}(\mathrm{O} 1)$ and $\mathrm{V}$ $(\mathrm{C} 4, \mathrm{C} 5)$. The fourth and final stage consists in the formation of the $\mathrm{C} 3-\mathrm{C} 4$ bond, the newly formed $\mathrm{V}(\mathrm{C} 3, \mathrm{C} 4)$ disynaptic basin taking its population from the disappearing $\mathrm{V}(\mathrm{C} 3)$ and $\mathrm{V}(\mathrm{C} 4)$ basins. All these flows are represented by curly arrows in Figure $9 \mathrm{C}$. 


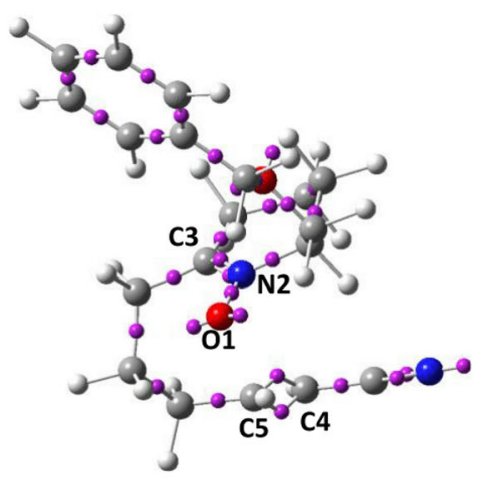

SSD-I

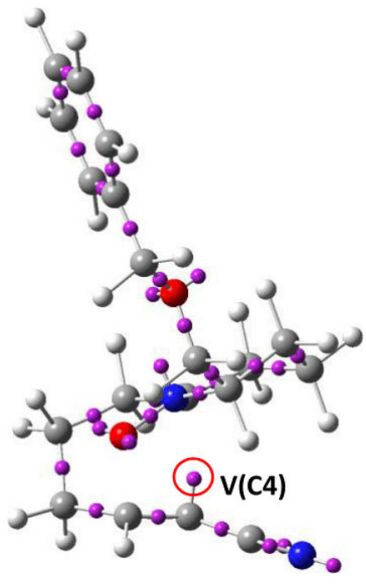

SSD-V

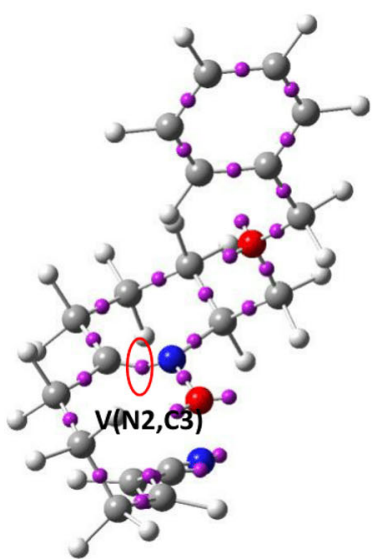

SSD-II

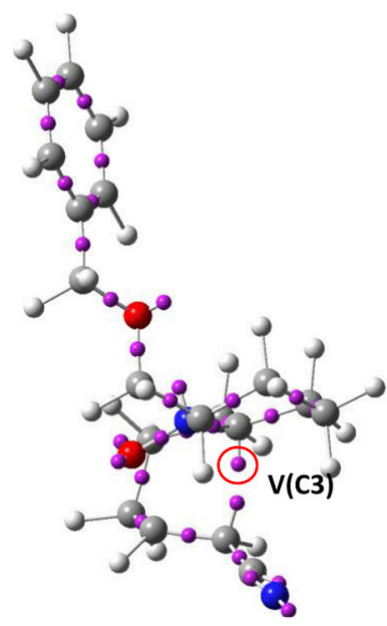

SSD-VI

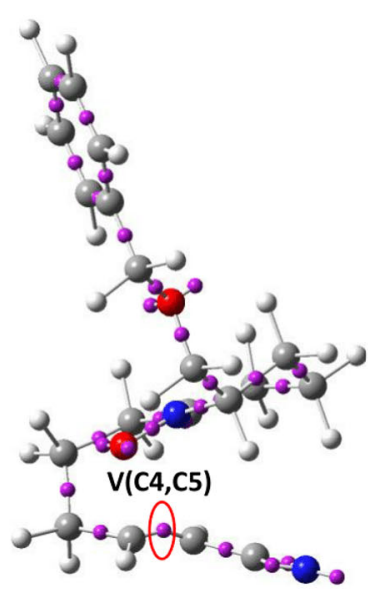

SSD-III

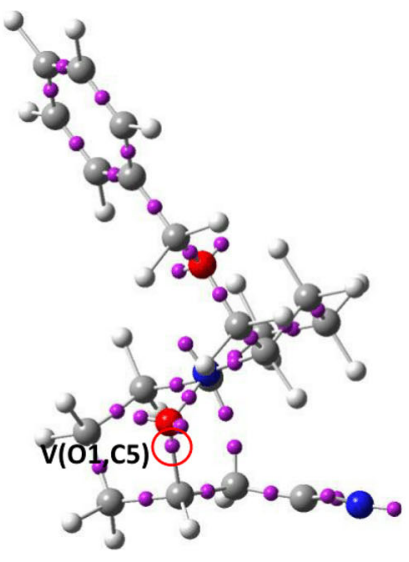

SSD-VII

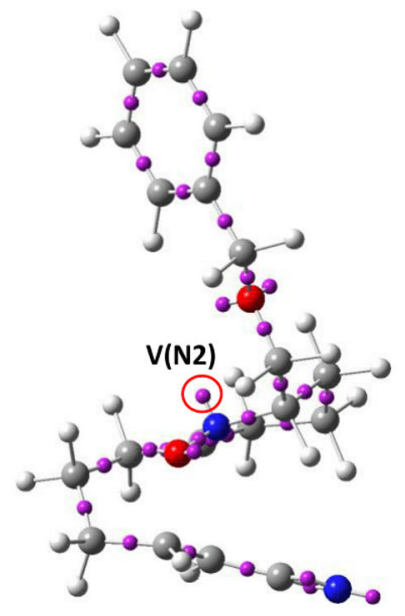

SSD-IV

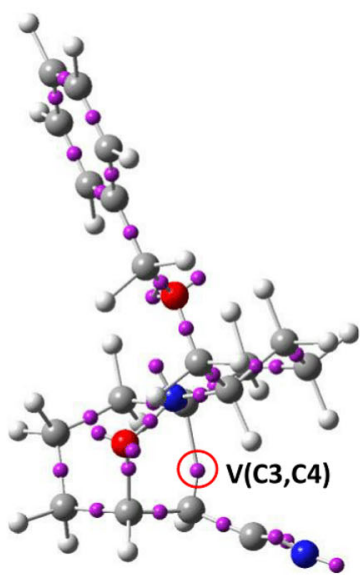

SSD-VIII

FIGURE 8 ELF attractor positions for selected points that are representative of each of the SSDs found along the IRC associated with TS-FN. SSD, structural stability domain

TABLE 1 Percentage of TS location along the IRC (\%IRC), number of domains found $(N)$, absolute synchronicities ( $S_{y}^{\text {abs }}$ ), and order in which the monosynaptic and disynaptic basins appear along the different reaction pathways

\begin{tabular}{|c|c|c|c|c|}
\hline & TS-BX & TS-FX & TS-BN & TS-FN \\
\hline$\%$ IRC & 55.45 & 71.19 & 77.40 & 73.57 \\
\hline$N$ & 6 & 7 & 8 & 8 \\
\hline$S_{y}^{a b s}$ & 0.642 & 0.881 & 0.843 & 0.895 \\
\hline Order & $\begin{array}{l}\text { Merg; V(C3) + V(N2) + Merg*; } \\
\quad \mathrm{V}(\mathrm{C} 5) ; \mathrm{V}(\mathrm{C} 3, \mathrm{C} 5)+\mathrm{V}(\mathrm{C} 4) ; \mathrm{V}(\mathrm{O} 1, \mathrm{C} 4)\end{array}$ & $\begin{array}{l}\text { Merg; Merg*; V(N2); V(C4); } \\
\quad \mathrm{V}(\mathrm{O} 1, \mathrm{C} 5)+\mathrm{V}(\mathrm{C} 3) ; \mathrm{V}(\mathrm{C} 3, \mathrm{C} 4)\end{array}$ & $\begin{array}{l}\text { Merg; Merg*; V(N2) + (VC3); V(C5); } \\
\quad \text { V(C3,C5); V(C4); V(O1,C4) }\end{array}$ & $\begin{array}{l}\text { Merg; Merg*; V(N2); V(C4); V(C3); } \\
\quad \text { V(O1,C5); V(C3,C4) }\end{array}$ \\
\hline
\end{tabular}

Note: "Merg" stands for the merging of the basins describing the double bond N2=C3, while "Merg*" refers to the merging of the basins describing the formally double $\mathrm{C} 4=\mathrm{C} 5$ bond.

Finally, in the fused endo case, via TS-FN, to attain CaF endo, the same description of the electron flows as in the TS-FX case can be performed, with only one difference, because there are five instead of four stages due to the fact that the formation of the $\mathrm{V}(\mathrm{C} 3)$ monosynaptic basin takes place before formation of the $\mathrm{O} 1-\mathrm{C} 5$ bond, as can be seen schematically in Figure 9D.

It is worth noting that in all four cases, the population of the $\mathrm{V}(\mathrm{O} 1, \mathrm{~N} 2)$ disynaptic basin experiences a diminution of around 0.5 |e| throughout the processes. This diminution mainly coincides with the growth of the $\mathrm{V}(\mathrm{N} 2)$ population, thus reflecting the conversion of the initial $\mathrm{N}-\mathrm{O}$ nitrone bond into a single and scarcely populated $\mathrm{N}-\mathrm{O}$ bond with a lone pair on $\mathrm{N} 2$ and two lone pairs on $\mathrm{O} 1$, and without the formal charge separation. 


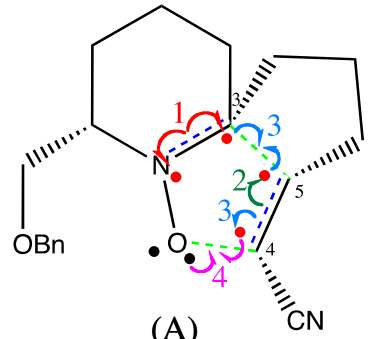

(A)

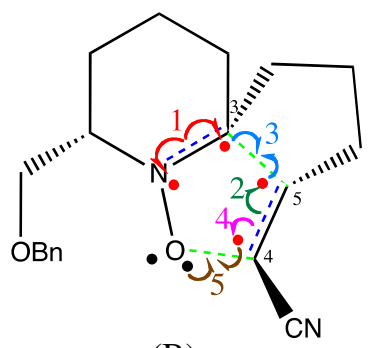

(B)

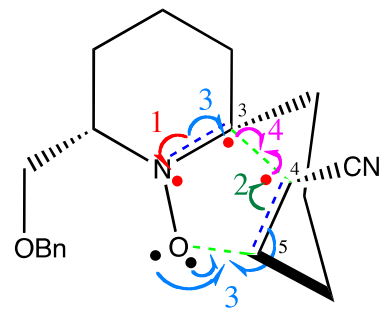

(C)

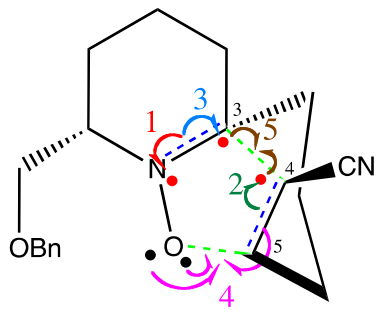

(D)
FIGURE 9 Flow of the electrons along the four reaction paths (A) through TS-BX, (B) through TS-BN, (C) through TS-FX, and (D) through TS-FN. Blue dashed lines represent disynaptic basins that disappear, green dashed lines stand for disynaptic basins appearing, and red dots for monosynaptic basins appearing, or appearing and disappearing, throughout the processes. Black dots stand for monosynaptic basins on the oxygen atom. Small black numbers refer to the numbering of the atoms, while large colored numbers indicate the order in which the different stages of the electron flows take place (see the text)

\section{4 | CONCLUSIONS}

From the molecular physical chemist's viewpoint, the most interesting aspects of a chemical reaction are its reaction rates, the underlying reaction mechanisms, the nature of the events related to the breaking/forming of chemical bonds, and the transformation of formally double to simple bonds or vice versa. In addition, understanding the electronic fluxes throughout this chemical process provides new insights into the factors controlling the associated energetic barriers. We believe that an analysis of BET, as described here, nowadays offers a strong tool to address these research directions. In addition, it allows curly arrows to be retrieved and visualized in order to describe the reaction mechanisms. We have applied this methodology to the cycloaddition reaction of cyclic nitrones, characterizing a sequence of steps that represent simple chemical events. By using BET we have obtained a great deal of fundamental knowledge, providing a better understanding on how the flow of electron density throughout the reaction progress takes place in the intramolecular [3 +2$]$ cycloaddition of cyclic nitrones. The main conclusions of the present work can be summarized as follows:

1. The description of the electron flows is slightly different for each of the reaction pathways studied. However, in the four cases, the process begins with the depopulation of the initial $\mathrm{C}=\mathrm{N}$ double bond to render the corresponding $\mathrm{C}-\mathrm{N}$ single bond, as well as the appearance of a lone pair on the $\mathrm{N}$ atom, and continues with the depopulation of the $\mathrm{C}=\mathrm{C}$ double bond, which evolves to a single bond.

2. The formation of the sigma bonds, $\mathrm{C}-\mathrm{C}$ and $\mathrm{C}-\mathrm{O}$, takes place once the transition state has been overcome. The $\mathrm{C}-\mathrm{C}$ bond formation precedes the $\mathrm{O}-\mathrm{C}$ bond formation event along the bridged pathways, while along the fused paths the $\mathrm{O}-\mathrm{C}$ bond formation process occurs first.

3. Curly arrow representations reflecting the timing of the electron flows to describe the reaction mechanism for the cycloaddition reaction of cyclic nitrones are obtained from the BET results.

4. This description includes the formation of transient "lone pairs" on some $C$ atoms, described with monosynaptic $V(C)$ basins, which disappear when the final $\mathrm{C}-\mathrm{C}$ and $\mathrm{O}-\mathrm{C}$ bonds are formed, thus revealing the intimate mechanism of the electron motions responsible for the formation of sigma bonds along the reaction pathway.

While this method has proven its value, it also has its limitations, such as the use of the IRC method to follow the reaction progress, which does not take into account anharmonicity and dynamic effects. This would require a significant number of calculations with a corresponding expenditure of computational time and resources, mainly caused by the need to compute nonadiabatic couplings. In particular, this problem is exacerbated if anharmonicity is to be included in the model, because numerical derivatives for each of the numerous nonadiabatic coupling matrix elements must then be evaluated, and the number of such derivatives increases with the number of atoms in the molecule. Therefore, this approach is only feasible for the smallest systems. Nevertheless, the advantages that would be obtained from this alternative formulation would certainly improve the usability of the method and extend its applicability to larger systems. We will therefore pursue this possibility in future work.

\section{ACKNOWLEDGMENTS}

Authors wish to thank the Consortium des Équipements de Calcul Intensif (CÉCI) and the Plateforme Technologique de Calcul Intensif (PTCI). Adjieufack thanks the University of Namur, Belgium, for his UNamur-CERUNA PhD Mobility Fellowship. Authors gratefully acknowledge financial 
support from the FNRS-FRFC (Conventions 2.4.617.07.F and 2.5020.11) and from the University of Namur. Andrés, Oliva, and Safont thank the Universitat Jaume I for UJI-B2016-25 research project as well as the Spanish Ministerio de Economía y Competitividad for research project CTQ2015-65207-P.

\section{ORCID}

Abel I. Adjieufack (D) https://orcid.org/0000-0001-8769-6036

Ibrahim Mbouombouo Ndassa (D) https://orcid.org/0000-0003-0714-4982

Vicent S. Safont (1D) https://orcid.org/0000-0003-2709-4230

\section{REFERENCES}

[1] S. Alvarez, R. Hoffmann, C. Mealli, Chem. Eur. J. 2009, 15, 8358.

[2] S. Shaik, H. S. Rzepa, R. Hoffmann, Angew. Chem. Int. Ed. 2013, 52, 3020.

[3] S. Shaik, H. S. Rzepa, R. Hoffmann, Angew. Chem. 2013, 125, 3094.

[4] R. F. W. Bader, T. T. Nguyen-Dang, Y. Tal, Rep. Prog. Phys. 1981, 44, 893.

[5] G. Frenking, A. Krapp, J. Comput. Chem. 2007, 28, 15.

[6] M. Fugel, J. Beckmann, D. Jayatilaka, G. V. Gibbs, S. Grabowsky, Chem. Eur. J. 2018, 24, 6248.

[7] P. W. Ayers, S. Fias, F. Heidar-Zadeh, Comput. Theor. Chem. 2018, 1142, 83.

[8] P. Hohenberg, W. Kohn, Phys. Rev. 1964, 136, B864.

[9] P. L. Ayers, R. J. Boyd, P. Bultinck, M. Caffarel, R. Carbó-Dorca, M. Causá, J. Cioslowski, J. Contreras-Garcia, D. L. Cooper, P. Coppens, C. Gatti, S. Grabowsky, P. Lazzeretti, P. Macchi, A. M. Pendás, P. L. A. Popelier, K. Ruedenberg, H. Rzepa, A. Savin, A. Sax, E. W. H. Schwarz, S. Shahbazian, B. Silvi, M. Solà, V. Tsirelson, Comput. Theor. Chem. 2015, 1053, 2.

[10] R. F. W. Bader, Atoms in Molecules - A Quantum Theory, Oxford University Press, Oxford, U.K 1990.

[11] P. L. A. Popelier, E. A. G. BrÉmond, Int. J. Quantum Chem. 2009, 109, 2542.

[12] X. Krokidis, S. Noury, B. Silvi, J. Phys. Chem. A. 1997, 101, 7277.

[13] D. Becke, K. E. Edgecombe, J. Chem. Phys. 1990, 92, 5397.

[14] R. Thom, Structural stability and morphogenesis, an outline of a general theory of models, Addison-Wesley, Reading, Massachusets 1975.

[15] I. Viciano, P. Gonzalez-Navarrete, J. Andrés, S. Martí, J. Chem. Theory Comput. 2015, 11, 1470.

[16] J. Andrés, L. Gracia, P. González-Navarrete, V. S. Safont, Comput. Theor. Chem. 2015, 1053, 17.

[17] P. González-Navarrete, J. Andrés, S. Berski, J. Phys. Chem. Lett. 2012, 3, 2500.

[18] V. Polo, J. Andres, R. Castillo, S. Berski, B. Silvi, Chem. Eur. J. 2012, 10, 5165.

[19] J. Andrés, P. González-Navarrete, V. S. Safont, Int. J. Quantum Chem. 2015, 119, 1239.

[20] A. Moyano, M. A. Pericas, F. Serratosa, E. Valentí, J. Org. Chem. 1987, 52, 5532.

[21] P. Vidossich, G. Ujaque, A. Lledós, Chem. Commun. 2012, 48, 1979.

[22] P. Vidossich, A. Lledós, Dalton Trans. 2014, 43, 11145.

[23] Y. Wu, S. Izquierdo, P. Vidossich, A. Lledós, A. Shafir, Angew. Chem. Int. Ed. 2016, 55, 7152.

[24] P. Vidossich, A. Lledós, Chem. Texts 2017, 3, 17.

[25] G. Knizia, J. Chem. Theor. Comput. 2013, 9, 4834.

[26] J. E. M. N. Klein, B. Miehlich, M. S. Holzwarth, M. Bauer, M. Milek, M. M. Khusniyarov, G. Knizia, H.-J. Werner, B. Plietker, Angew. Chem. Int. Ed. 2014, 53, 1790.

[27] J. E. M. N. Klein, B. Miehlich, M. S. Holzwarth, M. Bauer, M. Milek, M. M. Khusniyarov, G. Knizia, H.-J. Werner, B. Plietker, Angew. Chem. Int. Ed. 2014, $126,1820$.

[28] G. Knizia, J. E. M. N. Klein, Angew. Chem. Int. Ed. 2015, 54, 1.

[29] R. Ponec, J. Phys. Org. Chem. 2017, 30, e3706.

[30] L. Salem, Nouv. J. Chim. 1978, 2, 559.

[31] Y. Liu, P. Kilby, T. J. Frankcombe, T. W. Schmidt, Nature Communications 2018, 9, 1436.

[32] A. I. Adjieufack, I. Mbouombouo Ndassa, I. Patouossa, J. Ketcha Mbadcam, V. S. Safont, M. Oliva, J. Andrés, Phys. Chem. Chem. Phys. 2017, $19,18288$.

[33] A. I. Adjieufack, V. Liégeois, I. Ndassa Mbouombouo, J. Ketcha Mbadcam, B. Champagne, J. Phys. Chem. A. 2018, 122, 7472.

[34] V. S. Safont, P. González-Navarrete, M. Oliva, J. Andrés, Phys. Chem. Chem. Phys. 2015, 17, 32358.

[35] P. González-Navarrete, J. Andrés, V. S. Safont, Phys. Chem. Chem. Phys. 2018, 20, 535.

[36] J. Andrés, P. González-Navarrete, V. S. Safont, B. Silvi, Phys. Chem. Chem. Phys. 2017, 19, 29031.

[37] J. Andrés, S. Berski, B. Silvi, Chem. Commun. 2016, 52, 8183.

[38] A. Darù, D. Roca-López, T. Tejero, P. Merino, J. Org. Chem. 2016, 81, 673.

[39] M. Ríos-Gutiérrez, P. Pérez, L. R. Domingo, RSC Advances 2015, 5, 58464.

[40] M. Ríos-Gutiérrez, A. Darù, T. Tejero, L. R. Domingo, P. Merino, Org. Biomol. Chem. 2017, 15, 1618.

[41] L. R. Domingo, M. Ríos-Gutiérrez, P. Pérez, J. Org. Chem. 2018, 83, 2182.

[42] P. Merino, T. Tejero, I. Delso, R. Matute, Org. Biomol. Chem. 2017, 15, 3364.

[43] P. Merino, M. A. Chiacchio, L. Legnani, I. Delso, T. Tejero, Org. Chem. Frontiers 2017, 4, 1541.

[44] A. J. Hodges, J. P. Adams, A. D. Bond, A. B. Holmes, N. J. Press, S. D. Roughley, J. H. Ryan, S. Saubern, C. J. Smith, M. D. Turnbull, A. F. Newton, Org. Biomol. Chem. 2012, 10, 8963.

[45] L. R. Domingo, M. Ríos-Gutierrez, A. I. Adjieufack, I. Mbouombouo Ndassa, C. Nana Nouhou, J. Ketcha Mbadcam, Chemistry Select 2018,3 , 5412. 
[46] Y. Zhao, D. G. Truhlar, J. Phys. Chem. A 2004, 108, 6908.

[47] M. J. Frisch, G. W. Trucks, H. B. Schlegel, G. E. Scuseria, M. A. Robb, J. R. Cheeseman, G. Scalmani, V. Barone, G. A. Petersson, H. Nakatsuji, X. Li, M. Caricato, A. V. Marenich, J. Bloino, B. G. Janesko, R. Gomperts, B. Mennucci, H. P. Hratchian, J. V. Ortiz, A. F. Izmaylov, J. L. Sonnenberg, D. Williams-Young, F. Ding, F. Lipparini, F. Egidi, J. Goings, B. Peng, A. Petrone, T. Henderson, D. Ranasinghe, V. G. Zakrzewski, J. Gao, N. Rega, G. Zheng, W. Liang, M. Hada, M. Ehara, K. Toyota, R. Fukuda, J. Hasegawa, M. Ishida, T. Nakajima, Y. Honda, O. Kitao, H. Nakai, T. Vreven, K. Throssell, J. A. Montgomery Jr., J. E. Peralta, F. Ogliaro, M. J. Bearpark, J. J. Heyd, E. N. Brothers, K. N. Kudin, V. N. Staroverov, T. A. Keith, R. Kobayashi, J. Normand, K. Raghavachari, A. P. Rendell, J. C. Burant, S. S. Iyengar, J. Tomasi, M. Cossi, J. M. Millam, M. Klene, C. Adamo, R. Cammi, J. W. Ochterski, R. L. Martin, K. Morokuma, O. Farkas, J. B. Foresman, D. J. Fox, Gaussian16, revision A.03, Gaussian Inc, Wallingford, CT 2016.

[48] W. J. Hehre, L. Radom, P. V. R. Schleyer, J. Pople, Ab Initio Molecular Orbital Theory, Wiley, New York 1986.

[49] K. Fukui, J. Phys. Chem. 1970, 74, 4161.

[50] a) C. González, H. B. Schlegel, J. Phys. Chem. 1990, 94, 5523. b) C. González, H. B. Schlegel, J. Chem. Phys. 1991, $95,5853$.

[51] S. Noury, X. Krokidis, F. Fuster, B. Silvi, Comput. Chem. 1999, 23, 597.

[52] R. Dennington, T. Keith, J. Millam, GaussView, version 3, Semichem Inc, Shawnee Mission, KS 2009.

[53] V. Liégeois, DrawProfile. UNamur. www.unamur.be/drawprofile 2018.

\section{SUPPORTING INFORMATION}

Additional supporting information may be found online in the Supporting Information section at the end of this article.

How to cite this article: Adjieufack Al, Mbah Bake M, Ketcha Mbadcam J, et al. How effectively bonding evolution theory retrieves and visualizes curly arrows: The cycloaddition reaction of cyclic nitrones. Int J Quantum Chem. 2019;e25985. https://doi.org/10.1002/qua. 25985 